\title{
SPECULATION OF THE CYTOTOXIC EFFECT OF CISPLATIN EITHER NECROSIS OR APOPTOSIS AND THE POSSIBLE ANTAGONIST PROTECTIVE ROLE OF ACETYL L-CARNITINE, IN VITRO STUDY
}

\author{
Rasha Mohamed Taha* and Rania Hanafi Mahmoud Said**
}

\begin{abstract}
Background: Cisplatin is one of mostly used chemotherapeutic drugs. Eventhough, cisplatin drawbacks limit its use. Acetyl L- Carnitine is a neuro-protective and anti-oxidant agents as well as it has anti-apoptotic properties.

Aim of the study: this study was designed to evaluate the mechanism of Cisplatin to influence tissue in the pathway of apoptosis or the pathway of necrosis and the protective role of Acetyl-LCarnitine against cytotoxicity induced by Cisplatin in the dental pulp.

Material and methods: Total of 30 male albino rats (250-300 grams) were divided equally into three groups where saline was given to the control group (Group I), Cisplatin was injected into group II the (Cisplatin Group), and L- Carnitine was given to the Group III (L- Carnitine group + Cisplatin) before the injection of Cisplatin. After sacrificing the rats one week later, the extraction and preparation of their jaws were carried out in order to examine their dental pulp histologically histologically and immunohistochemically.
\end{abstract}

Results: The light microscopic results showed degeneration in the dental pulp tissue of group II animals represented by cytoplasmic vacuolization, idiopathic calcification, hyaline and fatty degeneration. While group III showed normal dental pulp tissues with dilated blood vessels. Immunohistochemical examination showed significant differences in group II when compared to control group for both Bax $(\mathrm{p}=0.0002)$ and TNF- $\alpha(\mathrm{p}=0.0029)$. No significant differences appeared in group III when compared to control group for both Bax and TNF- $\alpha$. Significant differences were evident in comparison between group II and group III for both $\mathrm{Bax}(\mathrm{p}=0.0015)$ and TNF- $\alpha$ $(\mathrm{p}=0.000001)$.

Conclusion: Cisplatin has a devastating effect on dental pulp tissues via both the apoptosis and necrosis pathways. L-Carnitine had a protective effect against the cytotoxicity of Cisplatin.

KEY WORDS: Cisplatin, L-Carnitine, BAX protein, Tumour Necrosing Factor.

* Lecturer in Oral Biology Department, Faculty of Dentistry, Suez Canal University

** Assistant professor in Oral Pathology Department, Faculty of Dentistry, Suez Canal University 


\section{INTRODUCTION}

One of the most commonly and broadly used medications of cancer treatment is Chemotherapy ${ }^{1}$ where the oral cavity is used to deliver antineoplastic agents as its cells have a high potential of proliferation. ${ }^{2}$ As a result, side effects such as mucositis and salivary hypofunction ${ }^{3}$ are caused and the progression of periodontitis ${ }^{4}$ can be accelerated. In turn, this could result in deteriorating individual's life quality significantly. ${ }^{3}$

One of the chemotherapeutics used to treat cancer is Cisplatin (Cisdiammine Dichloro Platinum II, CDDP, CIS). ${ }^{5}$ As the cells of cancer are targeted deficiently, the Cisplatin, which is bio-distributed to other organs, is considered the essence of the toxicity caused by Cisplatin. ${ }^{6}$ A number of cancers including testicular cancer, bladder, head and neck, lung and ovary cancers are treated using the Cisplatin and due to the severe lateral effects, the Cisplatin is used limitedly used clinically. This is because it could result in increasing the potential of toxicities such as nephrotoxicity, gastrointestinal toxicity, neurotoxicity and ototoxicity.?

As a result of the correlations of coordination between the platinum atom and the DNA of the cells, resulting in forming cross-links of DNA inside the chain, the Cisplatin produces the anticancer (cytotoxic) effects. In addition, such interaction between the Cisplatin and nuclear DNA can contribute to apoptosis by causing important cellular effects. The damage of cell death which is caused by Cisplatin via nuclear DNA damage is less important than the Mitochondrial DNA or other mitochondrial targets ${ }^{8}$.

The Cisplatin has an effect on calcium homeostasis and can result in an increase in the levels of intracellular calcium. ${ }^{9}$ In addition, the femoral head is often bilaterally ${ }^{10}$ affected by the avascular corruption at a rate of $1-2 \%$ in the longrun treatment of testicular cancer using Cisplatinbased chemotherapy. ${ }^{11}$
In the mitochondria, a molecule which could be derived from the acetylation of carnitine is AcetylL-Carnitine (ALC) where it plays a very important role in producing energy ${ }^{12}$. In addition, it could carry the mitochondria which are involved in oxidizing lipids, metabolizing glucose, decreasing systolic blood pressure, and increasing the sensitivity of insulin in patients with non-diabetic hypertension and high risk of cardiovascular ${ }^{13}$.

Therefore, such actions could lead to increase the efficiency and capacity of using the oxidative glucose and offsetting the movement of the substrate which is used from carbohydrates to lipids. ${ }^{14}$

In case of humans, food generates $75 \%$ of L-Carnitine while the basic amino acids lysine and methionine form the endogenous part of the kidney, liver and brain. Further, fatty acids are transported within the mitochondrial matrix after being activated in the cytosol to acyl-coenzyme A by involving the acetylation of Carnitine (ALC). Also, the acetylation of Carnitine contributes to eliminating oxidative products. ${ }^{15}$ Moreover; it generates acetyl groups and results in increasing the levels of intracellular Carnitine. Also, the ALC plays a crucial role in controlling mitochondrial acyl-CoA/CoA ratio and the peroxisomal oxidation of fatty acids. ${ }^{16}$

A large number of studies indicated that the ALC has a significant effect on cytotoxicity of Cisplatin while it does not interrupt its antitumor activity. Also, it is considered one of the safest and most well-tolerated medications in a number of clinical settings. ${ }^{17}$ This is due to its role in facilitating Acetyl-CoA movement in mitochondria when the fatty acids are oxidized in mammals. ${ }^{18}$ Additionally, it is considered the molecule which is commonly used as a dietary supplement for exercise. ${ }^{19}$

The ALC has a wide distribution in the tissue of mammals including brain and it is dynamically transported in the brain through the mediation of high-affinity organic cation/carnitine transporters (OCTN2 / OCTN3). The function of such 
transporters is expressed in the barrier between blood and brain and brain neurons and astrocytes. ${ }^{20}$

TheALCaffects the metabolismof mitochondrial energy positively and results in improving the processes of oxidizing and phosphorylating the Krebs cycle and the respiratory chain. ${ }^{21}$ It also has an aspect that affects the metabolic activity and has the effects of cytoprotection, anti-oxidation and anti-apoptotic in nervous system structure and mitochondria/peroxisome function which result in the inhibition of producing oxidants and inducing radical elimination activity. ${ }^{22}$

Furthermore, the ALC can lead to the strengthening the defense of mitochondrial antioxidation, protecting mitochondrial enzymes, stimulating the activity of enzymes. ${ }^{23}$ A lot of studies indicated that the neurotrophic and neuromodulatory effects of ALC provide acetyl groups to form and accelerate the cholinergic transmission. In turn, this causes a cholinergic impact and improves the balance of energy mechanism. Further, through the alternation of gene expression, the ALC could result in amalgamating proteins including those which are included in the expression of myelin stability or cytokine (nerve growth factor). ${ }^{24,25}$

\section{MATERIAL AND METHODS}

The present study was approved from the Research Ethics Committee, Faculty of Dentistry, Tanta University.

- The current study used a sample consisting of 30 healthy adult male albino rats (each weighed between 250 to $300 \mathrm{~g}$ ) which were kept in normal conditions of diet and water. The rats were distributed to three groups (10 rats in each group) as follows:

- Control Group (Group I): In this group, rats were injected with isotonic saline.

- Cisplatin group (Group II): In this group, a single intraperitoneal injection of $7 \mathrm{mg} / \mathrm{kg}$ of body weight was given to rats . Cisplatin ${ }^{\circledR}$ (MERCK generiques-France). ${ }^{26}$

- L-Carnitine and Cisplatin (Group III): In the third group, rats were given an intravenous injection of $500 \mathrm{mg} / \mathrm{kg}$ of L-Carnitine ${ }^{\circledR}$ (MEPACO-Egypt) before a single intraperitoneal injection of $7 \mathrm{mg} / \mathrm{kg}$ of Cisplatin ${ }^{\circledR}$ (MERCK Generics-France). ${ }^{26}$

One week later, in a closed vessel made of glass with cotton soaked in a lethal dose of diethyl ether, rats were sacrificed and their jaws were extracted and rapidly eliminated from the adherent connective tissue. Then, specimens were collected and immersed in $10 \%$ formalin after $24-48$ hours they were put in $10 \%$ EDTA (pH 7.4) - for bone decalcification- and the solution was changed every week for 3-5 weeks. The specimens were washed in (phosphate buffered saline) PBS and then embedded in paraffin. The embedding process was carried out by immersion in $70 \%, 80 \%, 96 \%$ ethanol (90 minutes each), three immersion in absolute ethanol (60 minutes each), two immersion in xylol (90 minutes each) and two immersion in liquid paraffin at $60^{\circ} \mathrm{C}(120$ minutes each). Finally, sections of $5 \mu \mathrm{m}$ thickness were obtained with a microtome and placed on adhesivecoated glass slides.

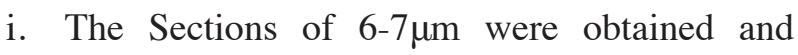
applied to clean glass slides and stained with Hematoxylin and Eosin stains in order to be examined using a microscope.

ii. The sections of thickness of $5 \mu \mathrm{m}$ were removed and applied to poly-lysine-coated slides. Then, they were prepared for Bax immunohistochemical staining in order to detect the apoptotic changes in the cells of dental pulp.

iii. Sections of the thickness of $5 \mu \mathrm{m}$ were removed and applied to poly-lysine-coated slides. Then, they were probed for the detection of immunohistochemical TNFa. Afterward, Stain was prepared for detecting necrotic changes in the pulp cells. 


\section{Immunohistochemical method used for detection of TNF- $\alpha$ and BAX:}

The Ultravisions mouse tissue detection system was the immunohistochemical detection system which was used: anti-mouse HRP / DAB bound to the primary antibody(monoclonal BAX mouse antibody (Anti-Bax) Sigma-Alrdich, Germany, and monoclonal TNF- $\alpha$ mouse antibody(Anti-TNF- $\alpha$, Sigma-Alrdich, Germany).

A streptavidin-biotin immune-enzymatic antigen detection system was formed by the reagents in the kit formed and the sequential incubation of the section was included in technique with a target nonconjugated primary antibody, i.e. the biotinylated secondary antibody which had a reaction with the enzyme of the streptavidin-DAB chromogenlabelled primary antibody.

\section{The immunostained sections were examined using}

a) To evaluate the proliferation of positive immunoreactivity for Bax and TNF- $\alpha$ in the pulp, an ordinary light microscope was used. Then, the optical density of Bax and TNF- $\alpha$ positive cells and the intensity of the immunostaining were assessed using the Image analyser computerized system.

b) To determine the optical density of cells which are positive for Bax and TNF- $\alpha$ and to measure the intensity of thire immunostaining, A computerized image analysis system was used. The processing of image analysis was carried out using a computer which had colored video camera, a colored monitor and a CBU that is linked to a microscope of an IBM PC. The first calibration of the image analyzer was run automatically in order to transform measurement units (pixels), which are produced by the program of image analyzer, to real micrometer units. With an increase of 400 , the optical density is used to measure reactions' intensity within cells in 10 small fields in each sample. Then, after the gray is calibrated, the image was transformed into a gray-framed image in order to choose the regions where the positive reactivity is shown with accumulating all reactivity levels (i. e, minimum, maximum and medium gray). Further, a red binary color was used to mask the positive areas. Finally, the mean values were calculated in each case. (Fig. 1(A\&B).

\section{Statistical analysis:}

In order to hold a comparison of the means of immunoreactivity of Bax and TNF- $\alpha$ between the control group and Cisplatin group and between the control group and the group treated with L-Carnitine + Cisplatin, the study used the Paired Student's t-test. In case the value of $p<0.05$, it is considered significant.

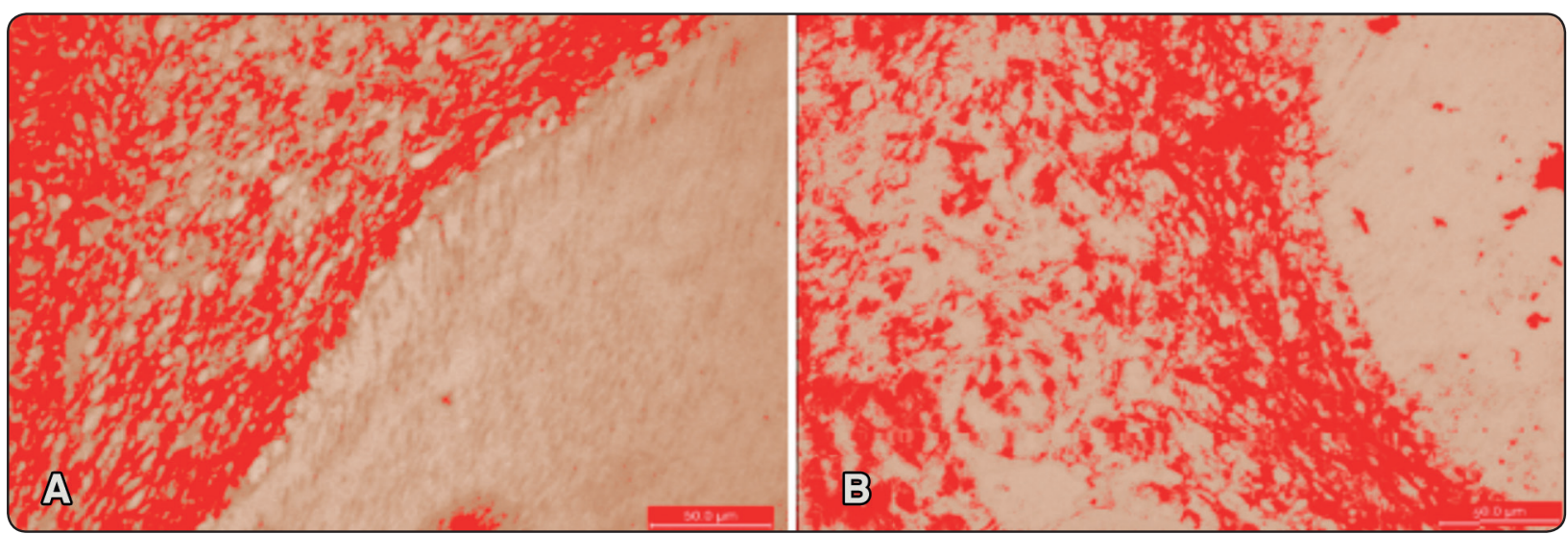

Fig. 1 (A): A copy of the screen which was displayed on the image analyzer screen where the optical density of Bax immunoexpression after being masked by a red binary color is shown.(B) : A copy of the screen which was displayed on the image analyzer screen where the optical density of TNF- $\alpha$ immunoexpression after being masked by a red binary color is shown. 


\section{RESULTS}

\section{I-Light microscopic picture of:}

\section{Group I:( Control)}

Light microscopic examination of pulp tissues of rats of group I (control group) revealed normal stratification of odontoblasts with normal connective tissue stroma and normal sized blood vessels (Fig.2)

\section{Group II: (Cisplatin)}

Examination of group II received single intraperitoneal dose of $7 \mathrm{mg} / \mathrm{Kg}$ b.wt. Cisplatin, showed areas of vacuolization and fatty degeneration of some odontoblasts and in other areas where

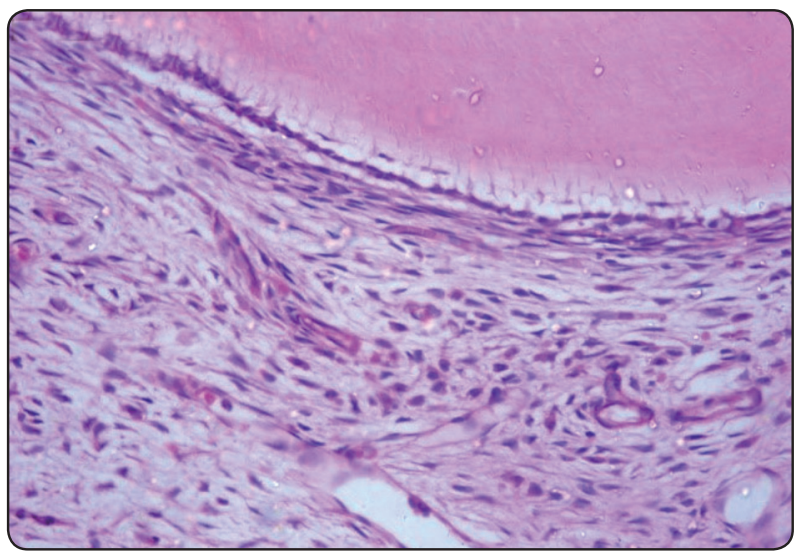

Fig. (2) A photomicrograph of normal pulp tissue (control group). (H\&E Orig.mag.X400)

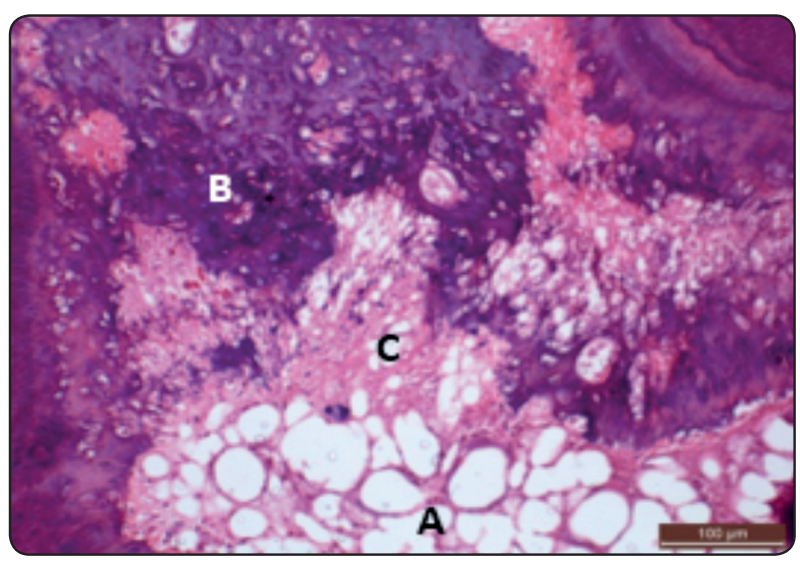

Fig. (3) A photomicrograph of pulp tissue of group II received Cisplatin showing vacuolization and fatty degeneration of some odontoblasts and the underlying C.T. (A), Idiopathic calcifications (osteodentine) (B) and fibrosis (C), (H\&E Orig.mag.X200) odontoblasts were overcrowding (Fig. 3 \& 5). Osteodentine appeared as idiopathic calcifications inside pulp tissues, fibrosis of pulpal connective tissue appeared with chronic inflammatory cells (Fig.3\&4) several dilated blood vessels of different sizes appeared filled with blood within areas of vacuolization and hyaline degeneration in dental pulp tissue core (Fig. 5 A\&B).

\section{Group III: (L-Carnitine + Cisplatin)}

The histological examination of group III that received a single dose of intraperitoneal injection of $500 \mathrm{mg} / \mathrm{kg}$ L-Carnitine before the intraperitoneal injection of $7 \mathrm{mg} / \mathrm{Kg}$ Cisplatin, revealed normal stratification and appearance of odontoblasts. Multiple dilated blood vessels appeared engorged with blood (Fig.6).

\section{II-Immunohistochemical examination:}

\section{Bax immunostaining:}

\section{Group I:}

Control group revealed faint cytoplasmic Bax immunoreactivity for some sporadic odontoblastic cells and few fibroblasts (Fig.7).

\section{Group II (Cisplatin):}

Immunohistochemical examination revealed intense cytoplasmic Bax immunoreactivity of odontoblasts, fibroblasts and macrophages (Fig.8).

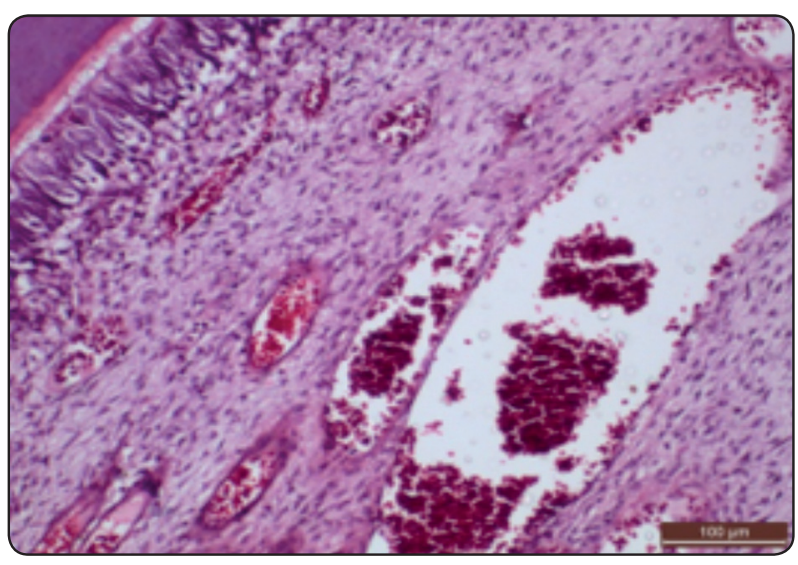

Fig. (4) A photomicrograph of pulp tissue of group II received Cisplatin showing dilated blood vessels engorged with blood, (H\&E Orig.mag.X200) 

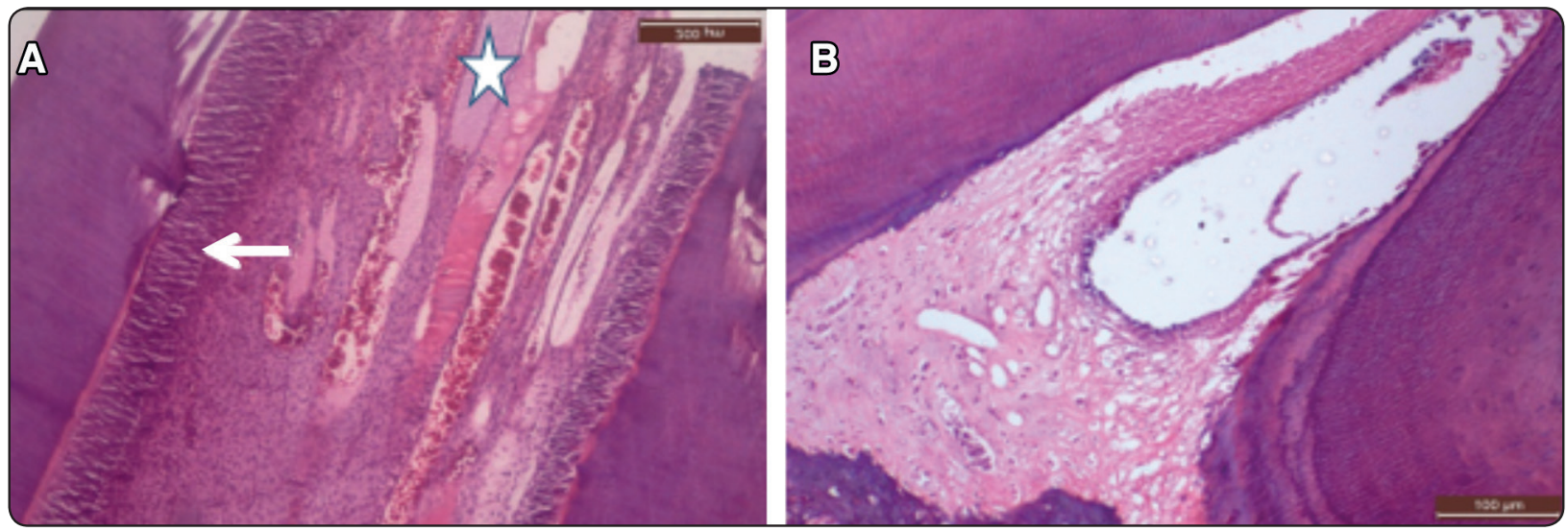

Fig. (5) A photomicrograph of pulp tissue of group II received Cisplatin showing (A) crowding in odontoblastic layer (arrow) and multiple dilated blood vessels engorged with blood and areas of hyaline degeneration (star), (B) cytoplasmic vacuolization in the connective tissue of pulp core(H\&E Orig.mag.X200)

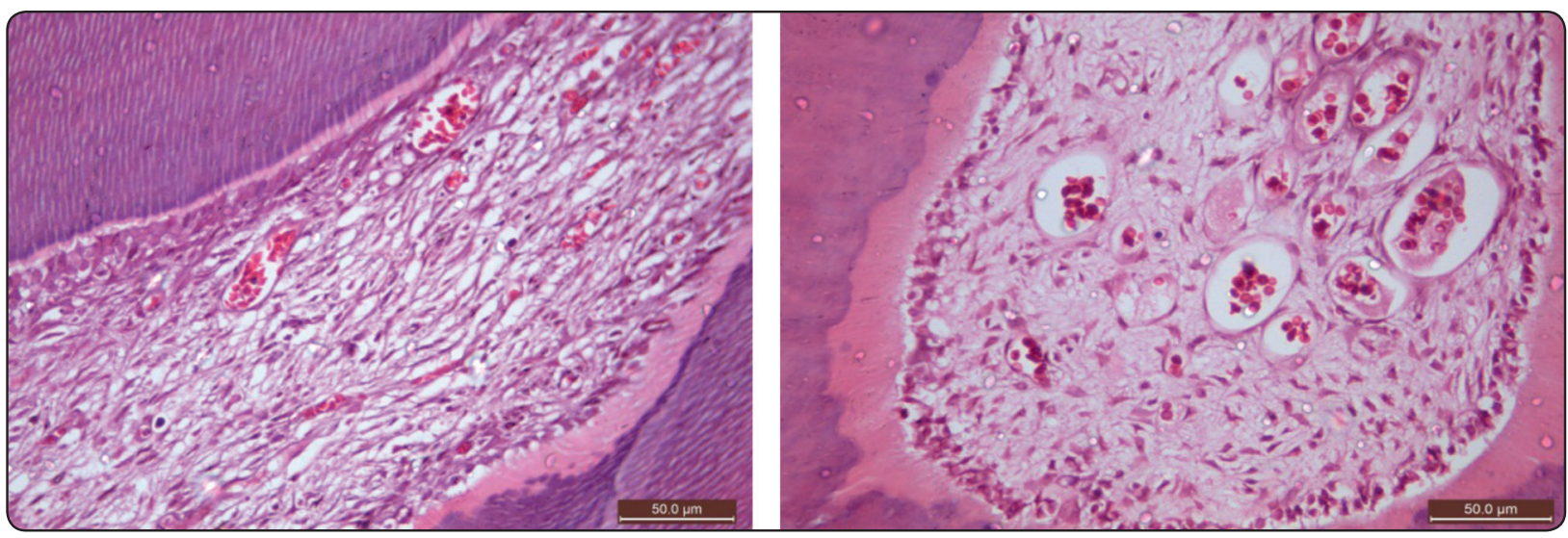

Fig. (6) A photomicrograph of pulp tissue of group III received L-Carnitine + Cisplatin showing normal stratification of odontoblasts but multiple dilated blood vessels engorged with blood, (H\&E Orig.mag.X200)

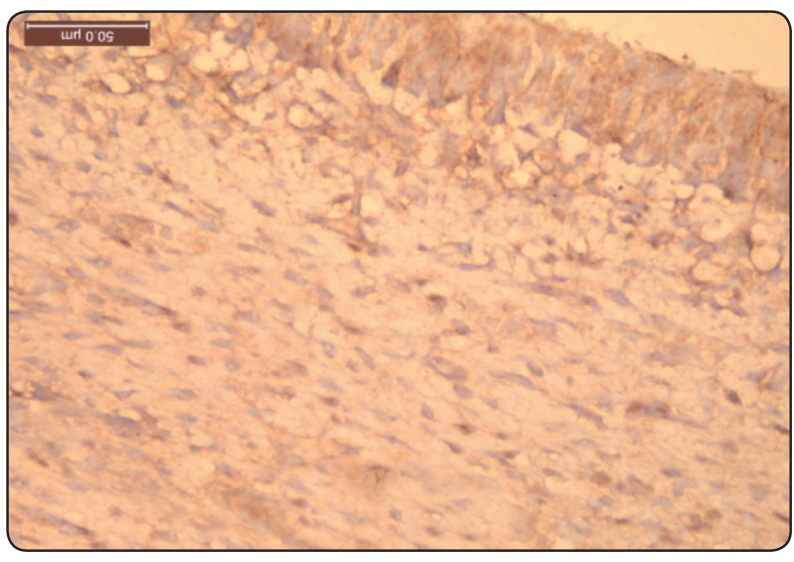

Fig. (7) A photomicrograph showing faint Bax immunoreactivity of some sporadic odontoblasts and fibroblasts group I (control group), (Bax Orig.mag.X200)

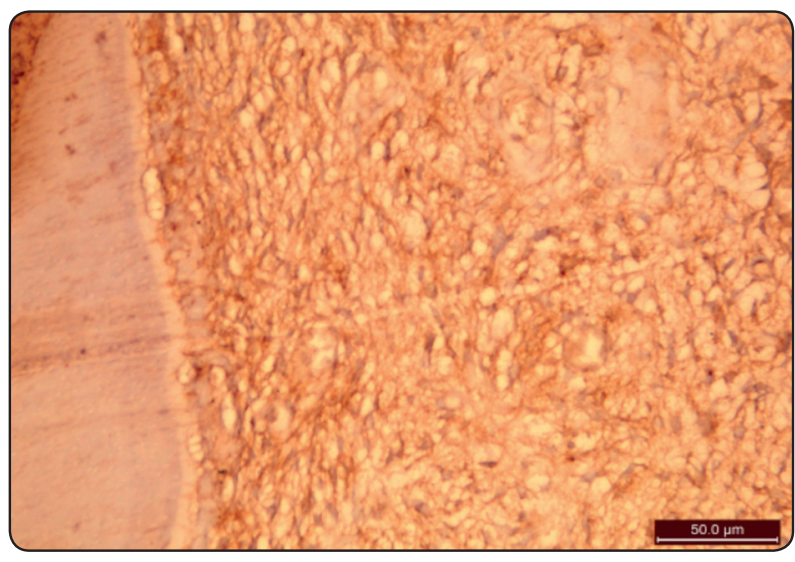

Fig. (8) A photomicrograph showing intense Bax immunoreactivity of odontoblasts, fibroblasts and macrophages group II, (Bax Orig.mag.X200) 


\section{Group III (L carnitine + cisplatin):}

Immunohistochemical examination revealed mild cytoplasmic Bax immunoreactivity of odontoblasts, fibroblasts and macrophages (Fig.9).

\section{TNF- $\alpha$ immunostaining:}

\section{Group I:}

Control group revealed faint cytoplasmic TNF- $\alpha$ immunoreactivity for some odontoblastic cells and few fibroblasts (Fig.10).

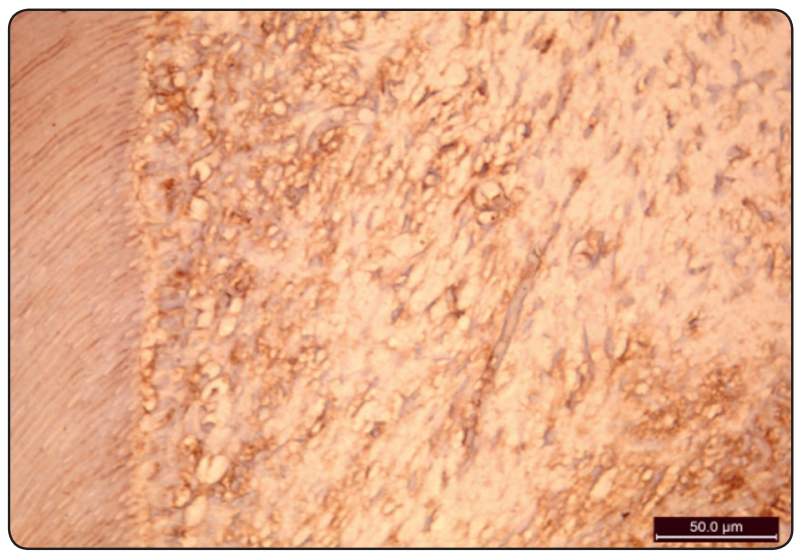

Fig.(9) A photomicrograph showing mild Bax immunoreactivity of odontoblasts, fibroblasts and macrophages group III, (Bax Orig.mag.X200).

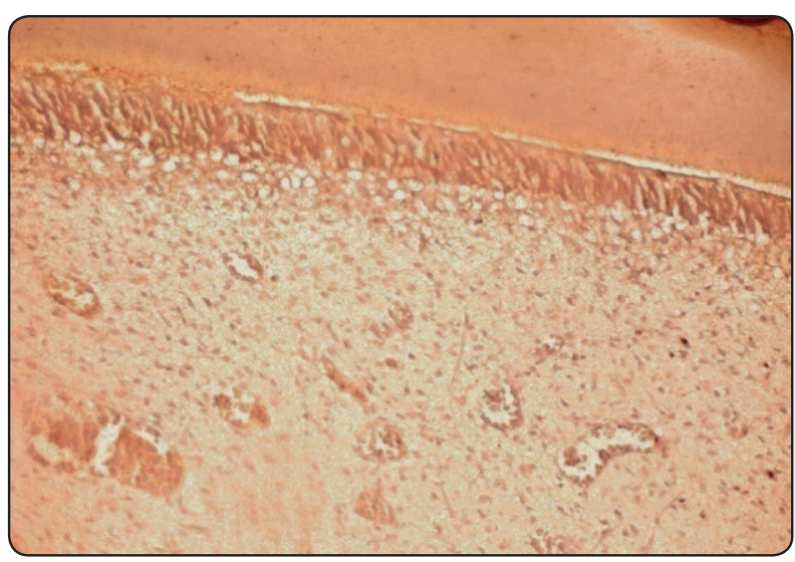

Fig. (11) A photomicrograph showing intense cytoplasmic TNF- $\alpha$ immunoreactivity of odontoblasts, fibroblasts and macrophages group II, (TNF- $\alpha$ Orig.mag.X200)

\section{Group II (cisplatin):}

Immunohistochemical examination revealed intense cytoplasmic TNF- $\alpha$ immunoreactivity of odontoblasts, fibroblasts and macrophages (Fig. 11).

\section{Group III (L carnitine + cisplatin):}

Immunohistochemical examination revealed mild cytoplasmic TNF- $\alpha$ immunoreactivity of odontoblasts, fibroblasts and macrophages (Fig. 12).

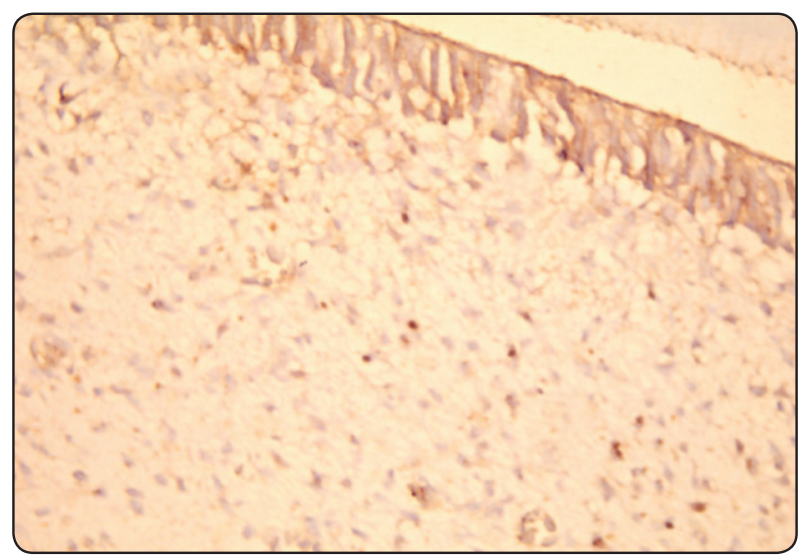

Fig. (10) A photomicrograph showing faint cytoplasmic TNF- $\alpha$ immunoreactivity of odontoblasts, fibroblasts and macrophages group I, (TNF- $\alpha$ Orig.mag.X200)

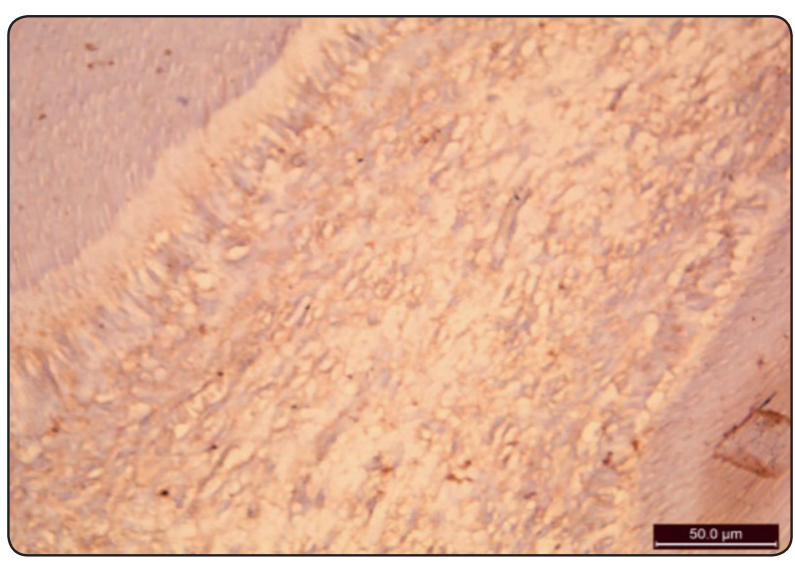

Fig. (12) A photomicrograph showing mild cytoplasmic TNF- $\alpha$ immunoreactivity of odontoblasts, fibroblasts and macrophages group III, (TNF- $\alpha$ Orig.mag.X200) 


\section{Statistical analysis:}

The results of Paired Student's t-Test Bax Protein indicated that the mean of optical density of the immunoreactivity of Bax protein has significantly increased in group II (Cisplatin group) compared to Group I (control group) where $\mathrm{P}=0.0002$ (Table I).

On the other hand, for Group III (L-Carnitine treated group), the mean optical density of the immunoreactivity of Bax protein has not increased significantly compared to Group I where $\mathrm{P}=0.1$ (Table II). The immunoracvtivity of Bax protein in group II was significantly different from that of Group III and $\mathrm{P}=0.0015$ (Table III). The mean of optical density of the immunoreactivity of Bax protein has significantly decreased in Group III compared to Group II (Histogram I).

TABLE (I) Difference in mean Bax optical density between control and Cisplatin groups using Paired Student's t-Test

\begin{tabular}{|c|c|c|c|}
\hline \multirow{2}{*}{ Group } & \multicolumn{3}{|c|}{ Optical Density } \\
\cline { 2 - 4 } & $\mathrm{M} \pm \mathrm{SD}$ & $\mathrm{t}$-Value & $\mathrm{p}$-Value \\
\hline Control & $74.9909 \pm 18.2119$ & & \\
\hline Cisplatin & $126.5172 \pm 29.3907$ & & 0.000277761 \\
\hline
\end{tabular}

Significant difference, $(p<0.005)$.

TABLE (II) Difference in mean Bax optical density between control and L- Carnitine + Cisplatin treated groups using Paired Student's t-Test

\begin{tabular}{|c|c|c|c|}
\hline \multirow{2}{*}{ Group } & \multicolumn{3}{|c|}{ Optical Density } \\
\cline { 2 - 3 } & $\mathrm{M} \pm \mathrm{SD}$ & t-Value & $\mathrm{p}$-Value \\
\hline Control & $74.9909 \pm 18.2119$ & & \\
\hline $\begin{array}{c}\text { L-carnitine } \\
\text { +cisplatin }\end{array}$ & $86.133 \pm 8.78095$ & 2.16037 & 0.104974906 \\
\hline
\end{tabular}

No Significant difference, $(p>0.005)$.
TABLE (III) Difference in mean Bax optical density between cisplatin and (L- Carnitine + Cisplatin) treated groups using Paired Student's t-Test

\begin{tabular}{|c|c|c|c|}
\hline \multirow{2}{*}{ Group } & \multicolumn{3}{|c|}{ Optical Density } \\
\cline { 2 - 3 } & $\mathrm{M} \pm \mathrm{SD}$ & $\mathrm{t}$-Value & $\mathrm{p}$-Value \\
\hline \multirow{2}{*}{ Cisplatin } & $\begin{array}{c}126.5172 \pm \\
29.3907\end{array}$ & & \\
& \multirow{2}{*}{2.20099} & \multirow{2}{*}{0.001580568} \\
\hline L-carnitine + & $86.133 \pm$ & & \\
cisplatin & 8.78095 & & \\
\hline
\end{tabular}

Significant difference, $(p<0.005)$.

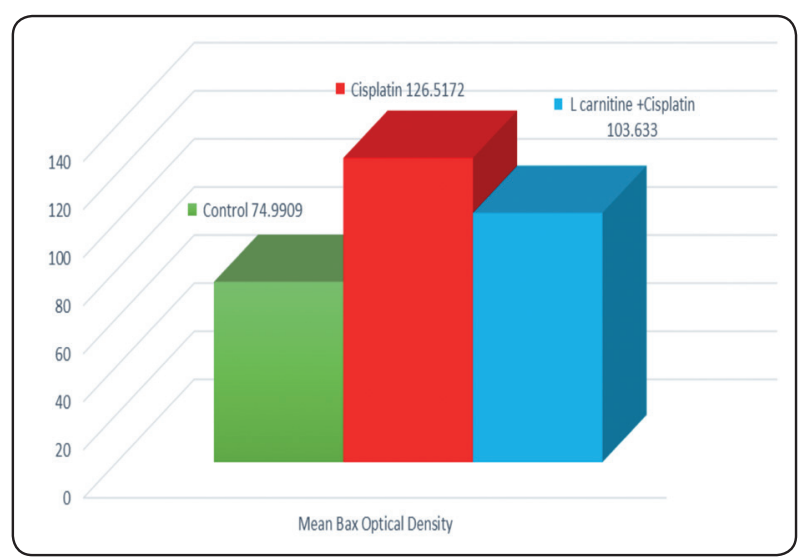

Histogram (I) Represents Difference in mean BAX optical density between different groups.

Furthermore, as indicated by the TNF- $\alpha$, the mean of optical density of the immunoreactivity of TNF- $\alpha$ protein has significantly increased in Group II (Cisplatin group) compared to group I (control group), $\mathrm{P}=0.0029$ (Table IV). However, the mean optical density of the immunoreactivity of TNF- $\alpha$ protein was not significantly different in Group III (L-Carnitine treated group) compared group I, $\mathrm{P}=0.57$ (Table V). As indicated by (Table VI), the immunoreactivity of TNF- $\alpha$ protein in Group II was significantly different from that of Group III, $\mathrm{P}=0.000001$. Finally, the mean of optical density of the immunoreactivity of TNF- $\alpha$ protein in Group III was significantly different from that of Group II (Histogram II). 
TABLE (IV) Difference in mean TNFa optical density between control and Cisplatin groups using Paired Student's t-Test

\begin{tabular}{|c|c|c|c|}
\hline \multirow[b]{2}{*}{ Group } & \multicolumn{3}{|c|}{ Optical Density } \\
\hline & $\mathrm{M} \pm \mathrm{SD}$ & t-Value & $\mathrm{p}$-Value \\
\hline Control & $16.2562 \pm 6.68347$ & \multirow{2}{*}{2.26216} & \multirow{2}{*}{0.002920882} \\
\hline Cisplatin & $25.4775 \pm 1.60934$ & & \\
\hline
\end{tabular}

Significant difference, $(p<0.005)$.

TABLE (V) Difference in mean TNF $\alpha$ optical density between controland L-Carnitine+Cisplatin treated groups using Paired Student's t-Test.

\begin{tabular}{|c|c|c|c|}
\hline \multirow{2}{*}{ Group } & \multicolumn{3}{|c|}{ Optical Density } \\
\cline { 2 - 3 } & $\mathrm{M} \pm \mathrm{SD}$ & $\mathrm{t}$-Value & $\mathrm{p}$-Value \\
\hline Control & $16.2562 \pm 6.68347$ & & \\
\hline $\begin{array}{c}\text { L-carnitine+ } \\
\text { cisplatin }\end{array}$ & $15.1812 \pm 3.50691$ & 2.17881 & 0.575100572 \\
\hline
\end{tabular}

No significant difference, $(p>0.005)$.

TABLE (VI) Difference in mean TNF- $\alpha$ optical density between Cisplatin and (L-carnitine+ Cisplatin) groups using PairedStudent's t-Test

\begin{tabular}{|c|c|c|c|}
\hline \multirow{2}{*}{ Group } & \multicolumn{3}{|c|}{ Optical Density } \\
\cline { 2 - 3 } & $\mathrm{M} \pm \mathrm{SD}$ & $\mathrm{t}$-Value & $\mathrm{p}$-Value \\
\hline Cisplatin & $25.4775 \pm 1.60934$ & 3.37247 & \multirow{2}{*}{0.000001241} \\
\hline $\begin{array}{c}\text { L-carnitine } \\
\text { + cisplatin }\end{array}$ & $15.1812 \pm 3.50691$ & & \\
\hline
\end{tabular}

Significant difference, $(p<0.005)$.

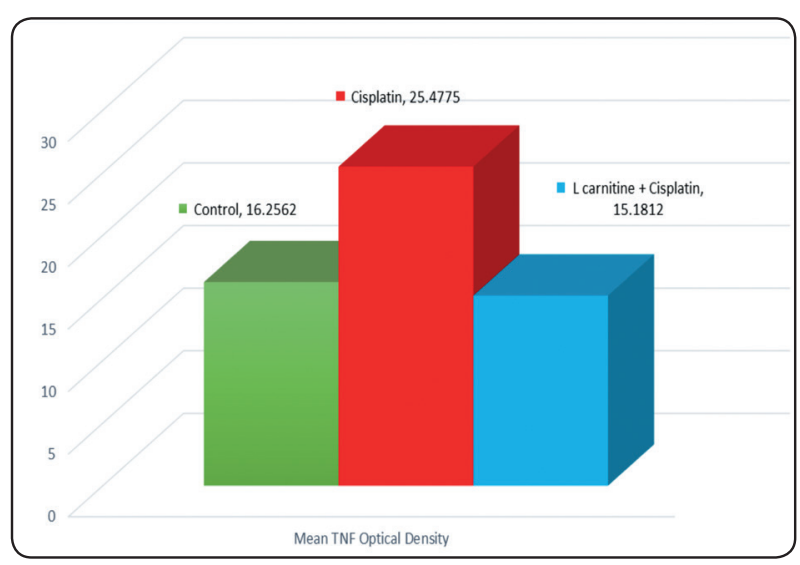

Histogram II: Represents Difference in mean TNF- $\alpha$ optical density between different groups

\section{DISCUSSION}

Cisplatin is one of the chemotherapeutic medications covalently bound to DNA with the purine base. It is primarily guanine in a cross-link which prevents transcription, arrests cell cycle and results in apoptotic effect. ${ }^{27}$

In addition, the reactive oxygen species are produced by the Cisplatin ${ }^{28}$ and its absorption in the DNA of nucleus results in linking the two adjacent guanines in the same DNA strand together, it prevents the synthesis of DNA and the death of cell. ${ }^{29}$ The apoptosis or the planned death of cell is correlated to the administrating a large number of anticancer medications including Cisplatin. Morphological alternations including cells shrinkage, cytoplasmic vacuolization, chromatin condensation and DNA fragmentation mark such active form of death of cell. In turn, this requires forming new proteins which are called "caspases". 30

In the current study, it appears that there is an effect of Cisplatin on the histological pattern of the pulp tissue. As indicated by the histological examination of the pulp, a single injection of Cisplatin showed fatty degeneration and vacuolization of some areas of odontoblastic layer, while it showed crowding in odontoblasts in some other areas. In the study of Jones et al., (2005), it was indicated that patients 
who are given doxorubicin (chemotherapeutic agent) show potential adverse effects on the formation of mineralized tissue formation within the pulp. In turn, this could have an effect on the rats of reparative dentin deposition within the tooth pulps. ${ }^{31}$ On the other hand, Karim, (1985) showed that in the rat incisor pulp, the formation of osteodentin took place after administering adriamycin (chemotherapeutic agent), leading pulp mesenchymal cells to be unusually differentiated. Additionally, he revealed that three days after the Adriamycin(Chemotherapeutic agent) is injected, mesenchymal cells were noticed along the pulp chamber walls. Then, during the period from 3 to 7 days, the osteodentin was noticed at sites in which the mesenchymal aggregations were observed. Then, using electron microscope to perform the examination, the results showed that the cells which are involved are larger aggregates. Further, compared to the unaffected pulp cells, the involved cells had more profiles for rough endoplasmic reticulum and secretory granules. The matrix of osteodentin was originally shown as a scant deposition of collagen fibres among cells and the density of the matrix become higher with the deposition of more collagen fibers. With increasing the deposition of matrix, cells originally forming the mesenchymal aggregates were fully enclosed..$^{32}$ The previous studies were compatible with our results as osteodentine appeared as an idiopathic calcification inside dental pulp after one weak of Cisplatin injection, which may be due to abnormal differentiation of mesenchymal stem cells of dental pulp tissues or may be as a sequlae of degeneration occurred in the pulp which represented by fibrosis hyaline and fatty degeneration. These alternations were thought to be results of the mechanism of action of Cisplatin that aimed for cell death. Fibrosis of pulpal connective tissue with chronic inflammatory cells was compatible with a previous study on the kidney that was noticed an increase in the chronic inflammatory cells and fibrosis induced by injection with Cisplatin ${ }^{33}$. A study of Jiang et al., (2014) reported that the DNA-damaging agent Cisplatin reduced the contractile function of thoracic aortas; and caused direct damage to vessel wall and cytotoxicity towards smooth muscle cells ${ }^{34}$. This study agreed with our results that showed multiple dilated blood vessels of different sizes engorged with blood that appeared with areas of vacuolization in pulp tissue core.

L-Carnitine is an essential amine in skeletal muscle metabolism as it is important in fatty acid metabolism, it regulates caspases activity and expression. As mentioned, caspases are essential in apoptosis ${ }^{35}$.

Within this investigation, the normal histological texture of dental pulp tissue in the group III which received Cisplatin injection after L-Carnitine dose confirmed that L-Carnitine played an anti-oxidant and anti-inflammatory role which protected the cells from the destructive effects of Cisplatin ${ }^{36}$. Furthermore, L-Carnitine antagonized the induced fibrosis caused by Cisplatin. As proofed by Mingorance et al. (2011), that vasodilation of subcutaneous arteries due to L-Carnitine administration, its mechanism is mediated primarily by production of "prostaglandins" from endothelial cells. However, it is a modest component of smooth muscle cells at higher concentrations. Therefore, the valuable cardiovascular effects of this compound might be in conjunction with vasodilation and a trial to improve blood flow. ${ }^{37}$. Our results agreed with Mingorance et al results, as in group III that received single dose of L-Carnitine before Cisplatin showed dilatation in blood vessels of the pulp core.

Induction of apoptosis with the Bax protein belongs to the $\mathrm{Bcl} 2$ family. The Bax protein is one of the best anti-apoptotic regulators that can regulate the production of apoptotic factors from mitochondria ${ }^{38}$. Bax protein exists in the cytoplasm of healthy cells. When the cell is subjected to a chemotherapeutic factor such as 
Cisplatin, the caspases transport the Bax protein to mitochondria $^{39}$. Chemotherapeutic agents such as Cisplatin stimulate and increase the overexpression of the Bax protein, which exerts an apoptotic effect on the cancer cells. This is demonstrated by our results, since the immunohistochemical localization of Bax in the dental pulp tissue of group II showed a significant difference compared to the control group ( $\mathrm{P}=0.0002)$, suggesting increased apoptotic changes in the cells. These results are in consistent with the results of an internal ear study, since the expression of Bax after the injection of Cisplatin was evident ${ }^{40}$.

Immunohistochemical study of group received L-Carnitine showed no significant difference in Bax immunoreactivity compared to the control group, suggesting the protective role of L-Carnitine against the destructive effect of Cisplatin.

Cisplatin administration upregulated chemokines and cytokines secreted by many leukocytes and which were responsible for Tumor Necrosis Factor $\alpha$ (TNF- $\alpha)$ release ${ }^{41}$. Immunohistochemical examination of tissues for TNF- $\alpha$ revealed a significant increase in TNF- $\alpha$ expression in pulp tissues after Cisplatin injection when compared to control. Whereas, no significant expression appeared for TNF- $\alpha$ in tissues when L-Carnitine was injected before Cisplatin. These results suggested that Cisplatin injection increased the TNF- $\alpha$ which was responsible for necrosis of tissues and that L-Carnitine had antagonistic effect on the release of TNF- $\alpha$ which implied the protective effects of L-Carnitine on pulp tissues. These results are consistent with the results of study performed on kidneys that showed Cisplatin caused nephrotoxicity which was induced by increase TNF- $\alpha$ produced from many leukocytes and immune cells ${ }^{42}$.

In conclusion, Cisplatin has a devastating effect on dental pulp tissues via both apoptosis and necrosis pathways. It is obvious from the results of this study that L-Carnitine has a protective effect against the cytotoxicity of Cisplatin as L-Carnitine acts as antioxidant and anti-inflammatory moreover it prevents fibrosis of pulp tissues if injected before Cisplatin.

\section{REFERENCES}

1. Karasawa T., and Steyger P.S. An integrated view of cisplatin-induced nephrotoxicity and ototoxicity. Toxicology Letters.2015;237:219-227.

2. Half, E., \& Arber, N. Colon cancer: Preventive agents and the present status of chemoprevention. Expert Opinion on Pharmacotherapy, 2009; 10: 211-219.

3. Kim, J. W., Cha, Y., Kim, S. J., Han, S. W., Oh, D. Y., Lee, S. H. amd Bang, Y. J. Association of oral mucositis with quality of life and symptom clusters in patients with solid tumors receiving chemotherapy. Supportive Care in Cancer, 2012; 20: 395-403

4. Garcia, V. G., Novaes, V. C. N., Almeida, J. M., Longo, M., Ervolino, E., Bomfim, S. R. M., \& Theodoro, L. H. Evaluation of the progression and treatment of experimental periodontitis in rats subjected to chemotherapy with 5-fluorouracil. Supportive Care in Cancer, 2015; 23 : 2007-2017.

5. Vermorken, J. B., Peyrade, F., KrausS, J., Mesía, R., Remenar, E., Gauler, T. C. and Clement, P. M. Cisplatin, 5-fluorouracil, and cetuximab (PFE) with or without cilengitide in recurrent/metastatic squamous cell carcinoma of the head and neck: Results of the randomized phase I/II advantage trial (phase II part). Annals of Oncology, 2014; 3: 682-688.

6. Banerjee S. Sinha K. Chowdhury and Sil P. Unfolding the mechanism of cisplatin induced pathophysiology in spleen and its amelioration by carnosine. Chemico-Biological Interactions. 2018; 279: 159-170

7. Sastry J1, Kellie SJ. Severe neurotoxicity, ototoxicity and nephrotoxicity following high-dose cisplatin and amifostine. Pediatr Hematol Oncol. 2005; 22:441-445.

8. Harris M.S. Gilbert J., Lormore K.A., Musunura S.A. and Fritsch M.H. Cisplatin ototoxicity affecting cochlear implant benefit. Otol Neurotol. 2011; 32:969-972.

9. Dasari S., and Bernard P.T.Cisplatin in cancer therapy: Molecular mechanisms of action. European Journal of pharmacology. 2014;740:364-378.

10. Tomaszewski A, Busselberg D. Cisplatin modulates voltage gated channel currents of dorsal root ganglion neurons of rats. Neurotoxicology. 2007; 28:49-58.

11. Fung C. and Vaughn D.Complications associated with chemotherapy in testicular cancer management. Nature Reviews Urology. 2011;8:213-222 
12. Shim K., Mackenzie M., and Winquist E. ChemotherapyAssociated osteonechrosis in cancer patients with solid tumours. Drug Saf. 2008; 31:359-371.

13. Sergi G. S. Piovesan P F., Trevisan C. N. Manzato V E. Effects of acetyl-1-carnitine in diabetic neuropathy and other geriatric disorders. Aging Clin Exp Res. 2018; 30: 133-138.

14. Laybutt D.R., Preston A.M., Akerfeldt M.C, Kench J.G., Busch A.K., Biankin A.V., and Biden T.J. Endoplasmic reticulum stress contributes to beta cell apoptosis in type 2 diabetes. Diabetologia. 2007;50 :752-763 Mingrone G. Carnitine in type 2 diabetes. Ann N Y Acad Sci . 2004; 1033:99-107.

15. Mingrone G. Carnitine in type 2 diabetes. Ann N Y Acad Sci . 2004; 1033:99-107.

16. Chiechio S, Copani A, Nicoletti F, Gereau RW 4th () 1-acetylcarnitine: a proposed therapeutic agent for painful peripheral neuropathies. Curr. Neuropharmacol., 2006; 64:233-237.

17. Traina G, Federighi G, Macchi M, Bernardi R, Durante $\mathrm{M}$, Brunelli M Modulation of myelin basic protein gene expression by acetyl-1-carnitine. Mol. Neurobiol., 2011; 44: 1-6.

18. Altun Z, Gunes D, Aktas S, Erbayrktar Z, Olgun N. Protective Effects of Acetyl-L-Carnitine on Cisplatin Cytotoxicity and Oxidative Stress in Neuroblastoma. Neurochem Res., 2010; 35:437- 444.

19. Chapela SP, Kriguer N, Fernández EH, Stella CA. Involvement of L-carnitine in cellular metabolism: beyond Acyl-CoA transport. Mini Reviews in Medicinal Chemistry, 2009; 9:1518-1526.

20. Miecz, Dorota \& Januszewicz, Elżbieta \& Czeredys, Magdalena \& Hinton, Barry \& Berezowski, Vincent \& Cecchelli, Romeo \& Nałęcz, Katarzyna. Localization of organic cation/carnitine transporter (OCTN2) in cells forming the blood-brain barrier. Journal of neurochemistry. 2008; 104:113-23.

21. Januszewicz E, Pajak B, Gajkowska B, Samluk L, Djavadian R, Hinton B, Nalecz K. Organic cation/ carnitine transporter OCTN3 is present in astrocytes and is up-regulated by peroxisome proliferators-activator receptor agonist. Int. J Biochem. Cell Biol, 2009; 41:2599-2609.

22. De Grandis D. Acetyl-L-carnitine for the treatment of chemotherapy-induced peripheral neuropathy. CNS Drugs, 2007; 21: 39-43.
23. Pisano C, Pratesi G, Laccabue D, Zunino F, Lo Giudice P, Bellucci A, Pacifici L, Camerini B, Vesci L, Castorina M, Cicuzza S, Tredici G, Marmiroli P, Nicolini G, Galbiati S, Calvani M, Carminati P, Cavaletti G Paclitaxel and cisplatin-induced neurotoxicity: a protective role of acetyl1-carnitine. Clin. Cancer Res., 2003; 9:5756-5767.

24. Traina G, Federighi G, Macchi M, Bernardi R, Durante M, Brunelli M. Modulation of myelin basic protein gene expression by acetyl-1-carnitine. Mol. Neurobiol., 2011; 44:1-6.

25. AL-Majed A. Carnitine defeciency provokes cisplatininduced hepatotoxicity in rats. Basic Clin. Pharmacol. Toxicol., 2007; 100: 145-150.

26. Siddik ZH. Cisplatin: mode of cytotoxic action and molecular basis of resistance. Oncogene, 2003; 22:72657279 .

27. Deavall D.G., Martin E.A., Horner J.M., and Roberts R. Drug-Induced Oxidative Stress and Toxicity. Review Article. Journal of Toxicology. Article ID 645460. 2012; 2012:1-13.

28. Zwelling L, Kohn K. Mechanism of action of cisdiammined ichloroplatinum II.Cancer Treat Rep., 1979;63:1439-1444.

29. Matsuhashi N, Saio M, Matsuo A, Sugiyama Y, Saji S. Apoptosis induced by 5-fluorouracil, cisplatin and paclitaxel are associated with p53 gene status in gastric cancer cell lines. Int J Oncol., 2005; 26: 1563-1567.

30. Yao X.M., Panichpisal K.M., Kurtzman N.M., and Nugent K.M. Cisplatin nephrotoxicity: A review. The American journal of the medical sciences. 2007; 334:115-124.

31. Jones T. E., Henderson J. S. and Johnson R. B. Effects of doxorubicin on human dental pulp cells in vitro Cell Biology and Toxicology. 2005; 21:207-214

32. Karim, Algernon. The initiation of osteodentin formation in the rat incisor after adriamycin administration. The Anatomical record. 1985; 213: 377-384.

33. Chang B, Nishikawa M, Sato E, Utsumi K, Inoue M. L-Carnitine inhibits cisplatin-induced injury of the kidney and small intestine. Arch Biochem. Biophys., 2002; 405:55-64. 
34. Jiang Y., Shan S. Gan T., Zhang X. ,LuX., Hu H., Wu Y., Sheng J., and Yang J. Effects of cisplatin on the contractile function of thoracic aorta of Sprague-Dawley rats. Biomed Rep, 2014; 2: 893-897.

35. Mutomba, M., Yuan, H., Konyavko, M., Adachi S., Yokoyama B. C., Esser, V., McGarry J.D., Babior M. B. and Gottlieb, R. Regulation of the activity of caspases by L-carnitine and palmitoylcarnitine. FEBS letters. 2000; 478: 19-25.

36. Sato S, Hori Y, Yamate J, Saito T, Kurasaki M, Hatai A. Protective effect of dietary azuki ean (Vigna angularis) seed coats against renal interstitial fibrosis of rats induced by cisplatin. Nutrition, $2005 ; 21: 504-511$.

37. Mingorance C., Rodriguez-Rodriguez R., Luisa M.J., Dolores M.H., and Alvarez M. Pharmacological effects and clinical applications of propionyl-L. Nutrition Reviews. 2011;69:279-290.

38. Wei M.C., Zong W.X., Cheng E.H., Lindsten T., Panoutsakopoulou V., and Ross A.J. Proapoptotic Bax and
Bak: a requisite gateway to mitochondrial dysfunction and death. Science. 2001; 292: 727-730

39. Lalier L., Cartron P., Juin P., Nedelkina S., Manon S., Bechinger B., and Vallette F. Bax activation and mitochondrial insertion during apoptosis. Apoptosis. 2007; 12: 887-896.

40. García-Berrocal J, Nevado J, Ramírez-Camacho R, Sanz $\mathrm{R}$ and González-García J. The anticancer drug cisplatin induces an intrinsic apoptotic pathway inside the inner ear. British Journal of Pharmacology, 2007; 152: 1012-1020.

41. Glabinski AR, Bielecki B, Kolodziejski P, Han Y, Selmaj K, Ransohoff RM. TNF-alpha microinjection upregulates chemokines and chemokine receptors in the central nervous system without inducing leukocyte infiltration. J Interferon Cytokine Res. 2003; 23:457-466.

42. Zhang, B. Ramesh G., Norbury C.C. and Reeves W.B. Cisplatin-induced nephrotoxicity is mediated by tumor necrosis factor- $\alpha$ produced by renal parenchymal cells. Kidney International J. 2007; 72: 37-44. 